VOL. LXV, NO. 270 .

\title{
THE JOURNAL
}

OF

\section{MENTAL SCIENCE.}

\section{EDTTORS :}

John R. Lord, M.B. Thomas Drapes, M.B.

\section{ASSISTANT EDITORS:}

Henry Dexine, M.D. $\quad$ G. Douglas McRae, M.D.

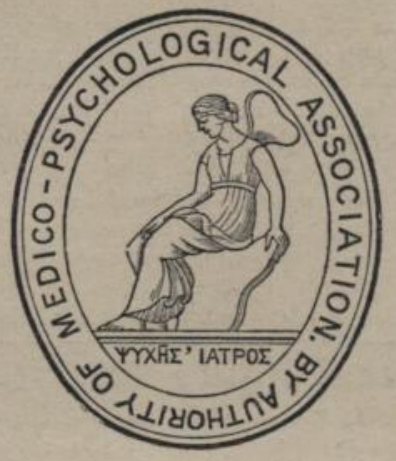

LONDON :

J. \& A. C H U R H I L L, 7, GREAT MARLBOROUGH STREET.

MSS. and Correspondence to be sent to Editors, Milleen, Dalkey Co. Dublin. Printed Matter to be sent to IMessrs. Churchill. Change of Address of Members to be sent to the General Secretary and to Messrs. Adlard \& Son \& West Newman, Ltd.

Published Quarterly, price Five Shillings net; or Twenty Shillings per annum net. 
JOURNAL OF MENTAL SCIENCE, JULY, 1919.

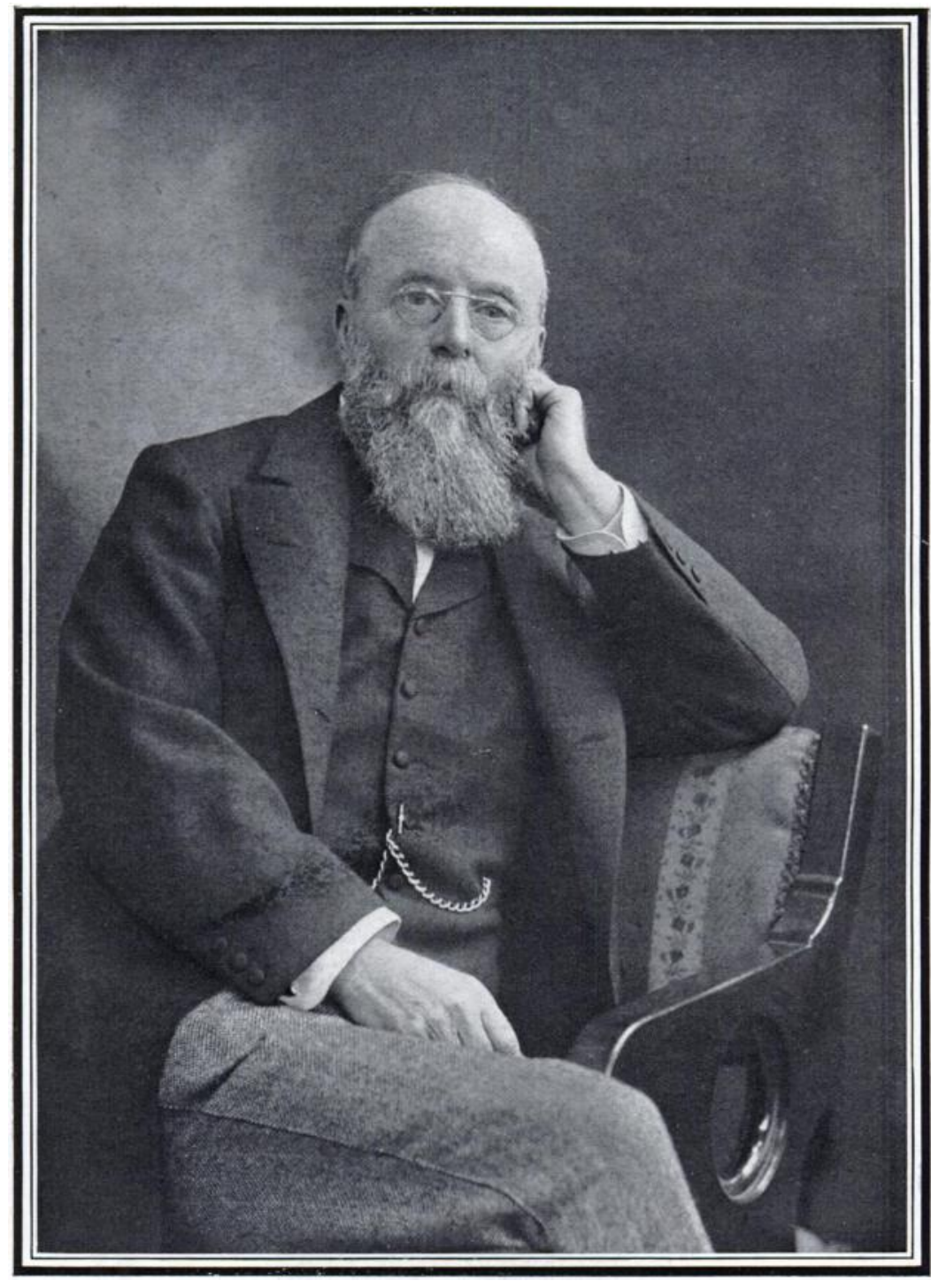

Joseph Wiglesworth, M.D., F.R.C.P.Lond.

Obiit May 16th, 1919. President, 1902-3. 